\title{
Serebral palsi hastalarında ayak sorunları
}

\author{
Foot problems in patients with cerebral palsy
}

\author{
Hakan Şenaran
}

Ortopedi ve Travmatoloji Uzmanı, Konya

\begin{abstract}
Bu derleme yazıda, serebral palsi hastalarında sık görülen ayak ve ayak bileği problemlerinin tarifi yapılmakta ve patogenezi anlatılmakta, tedavi seçenekleri hakkında bilgi verilmektedir. Tedavinin ilk basamağını fizik tedavi ve cihazlama oluşturmakla beraber, birçok deformite için spastisite azaltıcı ilaçlar ve cerrahi tedavi seçenekleri de gerekir. Tedavi şeması birçok faktörden etkilenir ve kişiye özeldir. Deformiteler zaman içinde şekil değiştirebilir; bu nedenle, cerrahi tedavi kararı verilmeden önce iyi planlama yapılması gerekir.
\end{abstract}

Anahtar sözcükler: serebral palsi; ayak; ayak bileği; ekinus; pesplanovalgus; pesekinovarus; ayak deformitesi; kavovarus
In this review article, the definition and pathogenesis of foot ankle deformities in cerebral palsy patients and their treatment strategies are summarised. Although the first line of treatment after diagnosis of cerebral palsy is always physical therapy and bracing, in most of the children, antispasticity medication and surgical treatment are also necessary. Treatment protocol should be individualized and multifactorial. Deformities may progress in time or structural changes occur; therefore, an exact and careful surgical decision making process is necessary.

Key words: cerebral palsy; pes equinovarus; equinus; pesplanovalgus; pescavovarus; foot deformity
$\Lambda$ yak ve ayak bileği sorunları serebral palsi (SP)'li çocuklarda \%92'ye varan oranlarda sıkça görülür. ${ }^{[1]}$ Bu sıklığın, kas dengesizliği, motor kontrolun bozulması ve yüksek kas tonusuna bağlı olduğu söylenebilir. Spastik kas grubu, normal veya zayıf karşı kas grubundan daha fazla güç üreterek, eklem etrafında anormal şekillenmelere neden olmaktadır. Zaman içinde, başlangıçta esnek olan şekil bozuklukları, yumuşak doku kontraktürüne ve kemik-eklem deformitelerine dönüş̧ebilir.

Genel olarak ayak deformiteleri ayak bileğinin pozisyonuna göre ekin ve kalkaneus, ayak arkasının pozisyonuna göre varus ve valgus, ayak ortasının pozisyonuna göre kavus ve planus, ayak önünün pozisyonuna göre adduktus ve abduktus deformiteleri olarak isimlendirilmektedir. Genellikle birkaç deformite aynı zamanlı gözlenir. En sık görülen deformiteler, ekin, planovalgus ve ekinovarus deformiteleridir. Ancak, yukarıda sayılan tekil deformitelerin her türlü kombinasyonu ile karşılaşılabilmektedir; ekinovalgus, kalkaneovalgus, ekinokavovarus gibi. Tedavi planlamasında temel prensipler benzerdir.
Ayak deformitelerinin tedavisinde, ortezler, kas tonusunu düşürecek işlemler ve cerrahi girişimler kullanılabilir. Germe egzersizleri tedavinin ilk basamağı olarak görülmektedir. Germenin etkinliği ise birçok çocukta sınırlıdır. ${ }^{[2]}$

Ortezlerin, ayak bileği ve ayak üzerindeki deforme edici kuwvetleri nötralize etmesi, bu eklemlerin uygun pozisyonda kalması için mekanik etkiyi oluşturarak yürüme mekaniği üzerine olumlu etki yapması amaçlanmaktadır. Ortezler kullanılıkları ekleme göre isimlendirilir. En sık kullanılan ortez, ayak bileğini uygun pozisyonda tutmak amacıyla diz altından parmaklara kadar uzanan ayak bileği - ayak ortezidir (AFO). Dizin üzerine kadar uzanan ortez ise KAFO olarak isimlendirilir. Mobilize SP hastalarında, mobilizasyonu kısıtlayabileceği ve ağırlığı nedeniyle çocuğa fazladan yük getireceği için, diz üzerine çıkan ortezler nadiren kullanılır. AFO, yürüme sırasında oluşacak dinamik ekin deformitesi gibi sagittal plan deformitelerinin nötralize edilmesinde oldukça yararlıdır. Salınım fazında ayağın yere temasını belli ölçüde kısıtlayarak yürüyüşe, durma fazında ise ayağın dorsifleksiyona ve valgusa gitmesini

- Iletişim adresi: Dr. Hakan Şenaran, Çandır Mah. Selbasançayı sok. No 6/U, Meram, Konya

Tel: 0505 - 0424242 e-posta: senaran@yahoo.com

- Geliș tarihi: 1 Ekim $2018 \quad$ Kabul tarihi: 1 Ekim 2018 
engelleyerek dik duruşun sağlanmasına katkıda bulunur. Farklı ortez şekilleri bulunmaktadır ve bu konunun ayrıntıları başka bir başık altında anlatılmaktadır.

Kas tonusu azaltılması amacıyla lokal ve genel metodlar kullanılır. Genel yöntem olarak sıklıkla baklofen, oral veya santral sinir sistemi üzerine intratekal kateter aracılığıla uygulanabilir. Fokal ton azaltılması ise özel kas ve kas gruplarına uygulanır. Bu amaçla, cerrahi olarak lumbar bölgede afferent sinir uçlarının tespiti sonrası kesilmesi (rizotomi) ameliyatları veya kas içine botulinum toksini enjeksiyonları uygulanabilir. Bu toksin nöromusküler bileşkede parsiyel ve geçici olarak asetilkolin salınımını engelleyerek, spastik kasta geçici denervasyon sağlar. Botulinum toksin enjeksiyonunun kasta hacim kaybına ve yapısal değişikliklere neden olduğu, dolayısıyla güç üretiminde sorun yarattığı ve fonksiyonel kapasiteyi olumsuz etkilediği konusunda yayınlar bulunmaktadır. Ancak, uygun rehabilitasyon ve güçlendirme ile bu sorunun altından kalkmak mümkün olabilir. ${ }^{[3]}$ Fenol ise sinir uçlarında nörolize neden olan proteolitik bir ajandır. Botulinum toksin ile kıyaslandığında fenol enjeksiyonu oldukça ağrılıdır ve uygulaması daha zordur. ${ }^{[4]}$ Fenol veya botulinum toksin uygulanarak fokal ton azaltılması işlemi, ancak dinamik ayak - ayak bileği deformitelerinde kullanılmalıdır. Kas kontraktürleri ve sert eklem deformitelerinde fokal ton azaltılması işlemleri kontraendikedir, çünkü ton azaltılsa bile eklem deformitelerinin ve kas kontraktürlerinin düzeltilmesi ve eklemlerin nötral şekline dönmesi mümkün olmayacaktır. Kural olarak, eklem pasif olarak nötral pozisyonuna getirilemiyorsa, fokal enjeksiyonların etkisi olmaz. En sık kullanılan kaslar gastroknemius, soleus ve tibialis posteriordur. Uygulamanın sedasyon altında yapılması ve uygulama sırasında sinir stimülatörü kullanılarak kasların doğru tespiti önemlidir. Fokal ton azaltıcı ilaçların uygulamalarının ayrıntılarına başka bir konu başlığı altında ayrıntılı değinilecektir.

Ayak deformiteleri ilerleyici ise cerrahi düzeltme işlemleri gerekebilir. Cerrahi tedavinin amacı, ağrısız, stabil ve plantigrad basan kuvetli bir ayak elde etmektir. Yumuşak doku girişimleri (tendon uzatma, tendon transferi, bağ ve eklem kapsülü gevşetme) ve kemik girişimleri (artrodez ve osteotomiler) uygulanabilir. Bu girişimlerden önce diğer eklemler mutlaka değerlendirilmelidir, diz veya kalça için de cerrahi girişim gerekiyorsa, tüm işlemlerin aynı seansta yapılması uygun olur. Ambulatuvar çocuklarda bu uygulama standart hale getirilmiştir. ${ }^{[5,6]}$

Ayak deformitelerinde prognoz, deformitenin ciddiyetine, çocuğun yaş ve hareket kapasitesine bağlı olarak değişmektedir. Kaba motor fonksiyon sistemi (GMFCS) sınıflandırmasına göre I-III arasında olan çocuklarda ayak deformitelerinin düzeltilmesinin ama$\mathrm{c}$, enerji tasarrufu ile ağrısız ve etkili bir yürümenin kazanılmasıdır. Grup IV ve V olanlarda ise rahat ayakkabı ve cihaz kullanımını sağlayarak, cilt yaralarının engellenmesidir.

\section{Ekin Deformitesi}

Ayak bileğinin ekini, SP hastalarının en sık görülen deformitesidir. ${ }^{[1]}$ Tanım olarak, ayak bileğinin pasif olarak $90^{\circ}$ ve üzeri dorsifleksiyona gelememesidir. Plantarfleksör kaslar olan gastroknemius ve soleus kaslarının, ayak bileği dorsifleksörü tibialis anterior kasına göre artmış tonusu sonucu gelişir. Ayak ortası ve önü nötral dizilimdedir. Ayak bileğinin $10^{\circ}$ plantarfleksiyonda sabitlenmesi, ciddi kinetik ve kinematik sorunlara neden olabilir. ${ }^{[7]}$ Genellikle önce dinamik deformite şeklinde başlar, bu aşamada germe egzersizleri ve ortezleme tedavileri uygulanır. Bu tedaviye ek olarak, yürüme dönemine geçecek çocuklarda ton azaltıcı fokal işlemler uygulanabilir. Enjeksiyon sonrası alçılama tartışmalı bir konu olmakla beraber, eğer yapılacak ise, gastroknemius üzerinde de etkili olması için dizin ekstansiyonda tutulması uygun olur. ${ }^{[8,9]}$ Plantarfleksör kaslarda kontraktür gelişmişse, cerrahi uzatma işlemleri uygulanmalıdır. Cerrahi uzatma işlemleri, kasların durumuna göre farklı bölgelerden yapılabilir. Bazı durumlarda izole gastroknemius kısalığı mevcut olduğu için, sadece muskülotendinöz bileşkeden yapılacak uzatmalar yeterlidir. İzole kısalığın tespiti için diz tam ekstansiyonda ve fleksiyonda iken pasif ayak bileği dorsifleksiyonu değerlendirilir. Diz fleksiyonda iken ayak bileğinin dorsifleksiyona gelmesi, ancak diz ekstansiyonda iken ekin kontraktürü görülmesi durumunda, yalnız gastroknemius kasına yönelik işlem gerekir. Böyle bir durumda Aşil tendonu üzerinden uzatma yapılırsa, plantarfleksiyon gücünde ciddi azalmaya neden olunabilir. Dizin pozisyonunun ayak bileği pasif hareketleri üzerinde etkisinin olmadığı görülürse, Aşil tendonunun uzatılması uygun olacaktır. Uzatma işlemi, tendon eksplorasyonu sonrası Z-plasti şeklinde yapılabileceği gibi, Aşil üzerinde küçük kesilerle tendonun perkütan uzatılması şeklinde de yapılabilmektedir. Perkütan uzatmalarda, uzatma sonrası tendonun devamlılı̆ının olması mutlaka kontrol edilmelidir. Uzatma ne kadar distalden yapılırsa, kas gücünde o kadar azalma ortaya çıkar. Ayrıca, tendonun fazla uzatılması da, ciddi kuvvet kaybına ve uzun dönemde kalkaneus deformitesinin gelişmesine neden olacaktır. Bu, geri dönüşü olmayan ciddi bir deformitedir ve ayak bileğinin itme fonksiyonunun kaybolması sonucu, yürüme mekaniğini bozarak, yürüme yeteneğinin kaybına neden olabilir; böylece, çömelme yürüyüşü ortaya çıkar. Diplejik çocuklar, fazla uzatma açısından risk altındadır. Bu çocuklarda 
genellikle izole gastroknemius kısalığına rastlanır ve uzatmanın mümkün olduğunca proksimalden yapılması tavsiye edilir. Ayrıca diz etrafı kasları dikkatlice değerlendirilmeli, ameliyat için mümkün olduğunca okul öncesi dönem beklenmelidir. Erken dönemde yapılan uzatmalarda sonucun kestirilebilirliği azalmaktadır. Deformitenin tekrarı veya kasın gereğinden fazla uzatılması ile karşılaşılabilir. Hemiplejiklerde ise genellikle Aşil kontraktürü görülür. İzole ekin deformitesi, cerrahi öncesi tedavi yöntemleri ile kontrol edilemiyor ve ilerliyorsa, ek deformitelerin özellikle kavus deformitesinin geliştiği görülüyorsa, hemiplejiklerde erken Aşil uzatma işlemleri yapılabilir. Genel kabul edilen yaklaşım, aşırı uzatmadan korunmak amacıyla cerrahi sonrası güvenli sınırda kalmak ve az miktarda ekin deformitesini kabullenmek yönünedir.

\section{Planovalgus Deformitesi}

Planovalgus deformitesi, sıklıkla diplejik ve kuadriplejik SP hastalarında görülür. ${ }^{[10]}$ Ayak arkasında valgus, ayak ortasında pronasyon, ayak önünde abduksiyon ve supinasyon mevcuttur. Zamanla, ayağın lateral kolonu, yapısal olarak mediyal kolonundan kısa hale gelir. Ayakta durma fazında, tarsal eklemler arasındaki kilitlenme kaybolur ve dolayısıyla ayak stabilitesi bozulur. Planovalgus deformitesi sıklıkla ayak arkasındaki ekin kontraktürü ile beraber görülür. Aşil kısalığı topuk valgusunun artmasına neden olur. Ayak dorsifleksiyonunun kısıtlanması da, basma fazının sonunda midtarsal eklemlerde anormal yüklenmeye ve ayak önünde abduksiyon deformitesinin gelişmesine neden olur. Tibiada diş rotasyon deformitesi zaman içinde gelişebilir ve ayakta kurvet kolunun bu şekilde zarar görmesi ile yürümede daha fazla bozulma görülür.

$\mathrm{Bu}$ deformite erken dönemde esnek olduğu için, ayak ortezleri kullanılabilir. Ortez kullanımı ayağı basma fazında stabilize ederek eklemlere anormal yüklenmeleri engellerken, uzun dönemdeki etkileri konusunda çok destekleyici çalışmalar bulunmamaktadır. ${ }^{[1]}$ Deformite zamanla, genellikle ambulatuvar çocuklarda kilo alma ve anormal yüklenmeler, ambulatuvar olmayan çocuklarda ise anormal kas dengesizliği nedeniyle ilerler. Cerrahi tedavi planlanırken ayağın üç boyutlu kompleks görüntüsü değerlendirilmelidir. Tedavinin amacı, stabil plantigrad bir ayak ve tarsal kemikler arasında doğru dizilimi elde ederek, yürüme sırasında kuvvet kolunun çok daha etkili çalışmasını sağlamaktır. Ambulatuvar çocuklarda, eklemlerin esnekliğinin ve hareketlerinin korunması önemlidir. Ayak ortasının stabilitesinin sağlanması gerekir. Evans tarafından tanımlanmış olan lateral kolon uzatma ameliyatı, ayağın dizilimini sağlamada oldukça etkilidir. ${ }^{[12-14]} \mathrm{Bu}$ ameliyat ile lateralde kalkaneusa açık kama osteotomisi yapılır ve lateral kolonun uzunluğu, mediyal kolon uzunluğuna eşit hale getirillir. Beraberinde peroneus brevis ve gastroknemiusa uzatma yapılabilir. Uzatma sonrası mediyal kolon tekrar değerlendirilir. Eğer supinasyon deformitesi devam ediyorsa, birinci metatarsa veya mediyal kuneiforma plantar fleksiyon osteotomisi yapılabilir. Daha ciddi deformitelerin varlığında, talonaviküler füzyon yapılarak stabilite sağlanabilir. ${ }^{[15,16]}$ Rathjen ve Mubarak tarafından tanımlanmış olan kalkaneo-küboid-kuneiform osteotomisi tekniği ile kalkaneusa mediyal kaydırma osteotomisi, küboide lateral açık kama osteotomisi, mediyal kuneiforma pronasyon ve plantar fleksiyon osteotomisi de ciddi planovalgus ayaklarda tercih edilebilir. ${ }^{[17]}$ Küçük ve ambulatuvar kapasitesi düşük olan çocuklarda, lateral kolon uzatma girişiminden sonra nüks sık görülür. ${ }^{[13,14]} \mathrm{Bu}$ hastalarda mediyal kolon stabilizasyonu veya subtalar artrodez uygulanabilir. ${ }^{[16]}$ Sert planovalgus deformitesi olan nonambulatuvar çocuklarda subtalar artrodez ile beraber mediyal kolon stabilizasyonu iyi sonuçlar vermektedir. ${ }^{[13,14]}$ Üçlü artrodez (talokalkaneal, talonaviküler, kalkaneoküboid) de ileri seviyede rijid deformitelerde kullanılabilir. ${ }^{[18]}$ Artrodezden sonra komşu eklemlerde artroz riski olduğundan, daha çok ambulatuvar olmayan çocuklarda tercih edilmelidir. Planovalgus deformitesinin düzeltilmesinin diz fonksiyonları üzerine olumlu etkisinin olduğu da gösterilmiştir. ${ }^{[18]}$

\section{Ekinovarus ve Ekinokavovarus Deformitesi}

SP hastalarında ekinovarus ayak deformitesi, ayak arkasında varus, ayak ortasında adduksiyon ve supinasyon ile beraber navikulanın talus başının mediyaline doğru subluksasyonu olarak tanımlanabilir. Genel olarak tibialis posterior spastisitesi ile beraber oluşacağı düşünülse de, tibialis anterior aşırı aktivitesinin de bu deformitenin gelişiminde önemli katkısı bulunmaktadır. ${ }^{[19]}$

Kavovarus deformitesinde ayak arkası varusu ile beraber, ayak önünün arkasına göre fleksiyona gitmesi mevcuttur. Planovalgus deformitesine benzer olarak ve paralitik deformitelerde gördüğümüz durumun tersine, SP hastalarında kavovarus deformitesine ekin kontraktürü eşlik eder. Ayak serttir, şoku emme özelliği yük taşıyan bölgenin azalması nedeniyle bozulmuştur. Ayağının lateraline ve anterioruna daha fazla yük biner ve bu şekilde deformitenin artmasına neden olur. Kavovarus genellikle hemiplejik çocuklarda görülmekle beraber, erken dönemde diplejik çocuklarda da görülebilir. Hafif ve esnek deformitelerde, genellikle ortez kullanımı yeterlidir. Ortez kullanımına rağmen deformite ilerler ve esnekliğini kaybederse, cerrahi tedavi seçenekleri ön plana çıkar. 
Nörolojik temele bağlı gelişen herhangi bir ayak deformitesinde tedavinin amacı; deformitelerin düzeltilmesi, eklemlerin diziliminin sağlanması, kas dengesinin sağlanması ile plantigrad bir ayak elde etmektir. Özellikle ekinovarus ve ekinokavovarus gibi ayak deformitelerinde, kas dengesizliğinin düzeltilmesi çok daha önemlidir. Kas uzatma, yumuşak doku gevşetme ve tendon transferleri esnek ayaklarda yeterli olur. Sert ayaklarda ise, yeterli düzeltme sağlamak için osteotomiler gerekir.

Tendon transferleri, SP'ye bağlı ekinovarus deformitesinin düzeltilmesinde temel cerrahi yöntemlerdendir. Esnek ayaklarda split tendon transferleri daha sık kullanılır. Tibialis anterior veya tibialis posterior tendonlarının yarısının yerinde bırakılarak, diğer yarısının ayak lateraline transferi sık uygulanmaktadır. Cerrahi işleme karar vermek bazı durumlarda oldukça zor olsa da, fizik muayeneye ek olarak, dinamik elektromiyografinin kullanıldığı yürüme analizi ve pedobarografi kullanılabilir. Ayrıca, deformitenin ortaya çıktığı dönem de önemlidir. Basma fazında ortaya çıkan deformitelerde split tibialis posterior transferi, salınım fazında ortaya çıkan deformitelerde ise split tibialis anterior transferi önerilmektedir. ${ }^{[20]}$ Tibialis posteriorun tümüyle laterale transferi, ambulasyonu yetersiz diplejik küçük çocuklarda kötü klinik sonuçlara ve geç dönem valgus deformitesine neden olacağı için önerilmemektedir. Yürüme analizinde, kasın ne zaman ateşlediğine bakılmalıdır. Eğer bir kas faz dışı ateşliyorsa, split transfer önerilir.

Osteotomiler, daha ciddi sert ekinovarus ve ekinokavovarus deformitelerinde gerekir. Temel deformite düzeltme prensipleri olan deformitenin apeksinin tespiti, deformitenin yerinin belirlenmesinde kullanılmalıdır. Kavus, adduktus ve rijid supinasyon deformitelerinin düzeltilmesinde, ayak ortası osteotomisi (küboid ve kuneiform), birinci metatars osteotomisi veya bazen talonaviküler ve birinci tarsometatarsal eklem artrodezi yapılabilir. Sabit ayak arkası deformitesi için lateral kaydırma komplet kalkaneal osteotomi, lateral tabanlı kapalı kama osteotomisi veya bunların kombinasyonu uygulanabilir. Çok daha sert ve ileri deformiteler için üçlü artrodez seçeneği bulunmaktadır.

\section{PATOGENEZ VE CERRAHI GIRIŞiMLER}

Ayak bileği ekin deformitesi serebral palsi hastalarında ilk dikkat çeken deformitedir. Kendisi de hemiplejik SP hastası olan İngiliz doktor Little, Aşil tendonuna yönelik ilk tenotomi ameliyatını 20. yüzyılın başlarında geçirdi. Ameliyatı Alman Stromeyer yaptı. Daha sonra serebral palsi hastalığı Little hastalığı olarak da anımaya başlandı. Aşil tendonuna uzatma, transfer ve daha çok o dönemde polio hastalarında uygulanmakta olan osteotomi ve artrodez ameliyatları da serebral palsi hastalarında uygulanmaya başlandı.

Yürüme analizi metodlarının 1980 yılından sonra gelişmesi ile, ayak deformitelerinin izole olmadığı, tüm alt ekstremiteyi etkilediği görüldü. Ekin deformitesi ile beraber veya aşırı uzamış Aşil tendonu ile beraber dizin pozisyonunun, tibia ve femurdaki rotasyonel deformitelerin değerlendirilmesi gerekti. Aynı şekilde, beraberinde kalça ve dize uygulanacak girişimler tanımlandı.

\section{Ekin Deformitesi}

Bildiğimiz gibi, ilk tedavisi yapılan deformite ekin deformitesidir. 1900'lü yıllarda Little, ekin deformitesinin tedavisini planlarken, aynı yıllarda Silfverskiöld kendi adıyla tanınan testini geliştirdi. Bu testte, ayak bileğinin dorsifleksiyonu, diz ekstansiyondayken ve fleksiyondayken ayrı ayrı değerlendirilir. Hem ekstansiyonda, hem fleksiyonda ekin kontraktürünün varlığı, Aşil tendonunda kısalık olduğunu göstermektedir. Bu durumda, açık veya kapalı perkütan yöntemlerle, Aşil tendonuna uzatma ameliyatları yapılabilir. Ayak bileğinin diz ekstansiyondayken dorsifleksiyona gelmemesi, ancak diz fleksiyondayken dorsifleksiyona gelmesi, kontraktürün dizi geçen kas olan gastroknemiusta olduğunu gösterir. Bu durumda Aşil tendonuna uzatma yapılmamalıdır. Bu, gastrosoleus kuvvetinde aşırı zayıflamaya neden olmaktadır. O nedenle proksimalden sadece gastroknemius kasına uzatma gerekir. Muskülotendinöz bileşkeye yapılan birçok tenomiyotomi ameliyatı tarif edilmiştir.

Ekinus deformitesinin nedeni, plantarfleksör kasların ayak bileği dorsifleksör kaslara göre 5-6 kat daha kuvvetli olmasıdır. Erken dönemde izole spastisite şeklinde ortaya çıkar. İzole spastisite varlığında; germe egzersizleri, cihaz ile pozisyonlama ve botulinum toksin enjeksiyonu ile takip uygun olur. İzole spastisite varlığında cerrahi işlem önerilmemektedir. Sabit kontraktür gelişimi sonrası ise botulinum toksin enjeksiyonunun yararı olmaz. Kontraktürün yeri Silfverskiöld testi ile tespit edilmeli ve cerrahi planlama hastanın yaşı göz önünde tutularak yapılmalıdır. Hemiplejik SP hastalarında erken dönemde izole ekin kontraktürü görülür. Konservatif tedaviden yarar görülmemesi durumunda, yaş gözetmeksizin tendon uzatma ameliyatı yapılabilir. Diplejik çocuklarda ise Aşil uzatma için acele edilmez. Genellikle beş yaşını doldurması beklenir. Beş yaş altı yapılan ameliyatların sonuçlarının kestirilemez olduğu düşünülmektedir. Ayrıca, erken dönemde ekinovarus deformitesi görülen diplejik çocuklarda, büyüdükçe deformitenin ekinovalgusa dönüşme ihtimali vardır. Diplejik ve kuadriplejik hastalarda kontraktür daha çok gastroknemius kasını ilgilendirirken, hemiplejik 
hastalarda Aşil kontraktürü görülür. Hemiplejik hastalarda erken dönemde izole Aşil kontraktürü görülürken, geç dönemde kavus deformitesi görülebilir. Tedavi planlamasında orta ayak sorunları da göz önüne alınmalıdır. Diplejik hastalarda ise geç dönemde ekin deformitesine ayak ortasında çökme, planovalgus deformitesi eşlik etmektedir. Bu durum tedavi edilmediği takdirde, ileri yaşlarda çömelme yürüyüşü gözlenebilir. Tüm deformitelerde ameliyat öncesi anestezi altında son muayene yapılmalı, dinamik deformite ile sabit deformite ayırt edilmelidir. Aşiloplasti ameliyatının en önemli komplikasyonu kalkaneus deformitesidir. Aşil'in fazla uzatıldığı durumlarda görülür. Ayak bileğinin plantar fleksiyon kuvveti ortadan kaybolur ve basma fazının sonunda kuvvet üretemez, dizde fleksiyon kontraktürü ile birlikte çömelme yürüyüşü ortaya çıkar. Kalkaneus deformitesinde ayağın dorsifleksiyonuna izin vermeyen ortez kullanılabilir. Ayrıca, tibialis anteriorun Aşil'e transferi yapılsa da yüz güldürücü sonuçlar elde edilememiştir. En sık görülen komplikasyon ise ekin kontraktürünün tekrar etmesidir. Bazı yazılarda, \%25-40'a kadar nüks ve ikincil cerrahi girişim bildirilmektedir. Beş yaş altı diplejiklerde yapılan Aşiloplasti ameliyatlarında nüks oranı daha fazladır. Ancak deformitenin nüksü, kalkaneus deformitesi gelişimine göre daha kabul edilebilir bir komplikasyondur. Aşiloplasti sonrası genellikle üç hafta alçı tedavisi uygulanır. Gastroknemius uzatma girişiminden sonra ise bir hafta alçı uygulaması, ardından kuvvetlendirme egzersizleri yapılmaktadır.

\section{Subtalar ve Orta Ayak Deformiteleri}

Ekin deformitesi en sık karşılaşılan deformite olsa da, ekinovarus ve ekinokavovarus deformiteleri de sık görülmektedir. Tibialis anterior ve tibialis posterior kasları, deformite gelişiminde temel etkendir. Elektromiyografı (EMG) çalışmaları ile bu bulgular desteklenmiştir. Planovalgus deformitesi de sık görülmekle beraber, bu deformitenin gelişimindeki temel etken değişkendir.

Ekinovarus ve planovalgus deformiteleri aynı eksende ortaya çıkan iki zıt deformitedir. Dinamik kas dengesinin sağlanmasındaki zorluk nedeniyle, ayağı nötral pozisyonda dengelemek çok zordur. Bunun nedeni, subtalar eklemin stabilizasyonunu sağlayan yapıların çok yetersiz olmasıdır. Eklemin stabilitesini temel olarak kas aktivitesi sağlamakla beraber, ayak bileğinin koronal deformitesi de etkili olmaktadır. Ayak bileğinin plantarfleksiyona gelmesi, subtalar eklemi varusa; dorsifleksiyona gelmesi subtalar eklemi valgusa çeker. Ayrıca, kas kuvvetleri değerlendirildiğinde kuvvetli spastisite subtalar eklemi varusa, ayakta dururken basma kuvvetleri subtalar eklemi valgusa zorlamaktadır.

\section{Ekinovarus}

Ortopedik literatürde oldukça sık yer almasına rağmen, subtalar eklem problemlerinin \%20'sini oluşturur. Planovalgus deformiteleri daha sık görülür. Hemiplejiklerde ekinovarus \%90'ın üzerinde, diplejiklerde planovalgus deformitesi \%60'ın üzerinde görülmektedir. Tibialis posterior kası, ayak bileği plantarfleksiyonuna ek olarak ayak önünü ve arkasını varusa getirir. Tibialis posteriorun antagonist kası peroneus brevistir. Tibialis anterior kası da öncelikle ayak önünü varusa çekmekte, ancak dolaylı olarak ayak arkası da varusa gelmektedir. Tibialis anteriorun varus kuvvetinin antagonist kası peroneus longustur ve yarısı kurvetindedir.

Erken dönemde görülen dinamik deformiteler, germe egzersizleri, ortez ve pozisyonlama ile kontrol edilmeye çalışılır. Selektif olarak tespit edilen deforme edici kaslara ve gastrosoleus kompleksine botulinum toksin enjeksiyonu yapılabilir. Hemiplejik hastaların küçük bir bölümünde varus deformitesi zamanla konservatif tedavi ile kontrol altına alınabilir. Ancak, diplejik hastalarda erken dönemde görülen varus deformiteleri, zaman içinde hemen tamamen valgusa dönmektedir. Hemiplejik hastalarda varus deformitesine yönelik intramusküler tibialis posterior uzatma planlanabilir. Ileri yaşlarda varus deformitesi sertleşmeye, 5. metatars üzerinde kallus oluşumuna ve ağrıya neden olur. EMG ile tibialis posterior kasının basma fazı sırasında veya sürekli aktif olduğunun gösterilmesi durumunda, split peroneus brevis tendonuna transferi planlanabilir. Bu hastalardaki deformitenin ameliyattan önce pasif olarak nötral pozisyona düzelebiliyor olması gerekir. Sabit deformiteleri tendon transferi ile düzeltmek mümkün değildir. Eğer varus deformitesi salınım fazında daha aktif ise tibialis anteriorun split olarak peroneus tertiusa veya longusa transferi düşünülebilir. Eğer her iki kasta da aktivite görülüyorsa, ikisinin de split transferi uygulanabilir. Cerrahi sonrası yük verebileceği şekilde kısa bacak alçısı yapılır ve dört hafta alçı içinde koruma sağlanır.

Sabit topuk varusu varsa, genellikle pasif olarak topuğu nötrale getirmek mümkün değildir. Sabit deformitelerin düzeltilmesi için osteotomi gerekir. Eğer primer deformite ayak arkasında ise, Dwyer lateral kaydırma kalkaneal osteotomisi veya lateral kapalı kama kalkaneal osteotomi yapılabilir. Kapalı kama osteotomisinde kalkaneus küçüleceğinden, kaydırma osteotomisi tercih edilmelidir. Eğer primer deformite orta ayakta ise, lateralde kalkaneoküboid eklem eksizyonu ile topuk varusu düzeltilebilir. Ayrıca, tibialis posterior tendonuna da Z-uzatma yapılmalıdır. Akıldan çıkarılmaması gereken bir kural, ayağın ameliyathanede kazandığı pozisyonun en iyi pozisyon 
olduğudur, ameliyattan sonraki dönemde aynı pozisyonu korumak zordur. O nedenle, maksimum düzeltmeyi ameliyat sırasında kazanmak gerekir. Daha ileri deformitelerde ise ayak arkası osteotomisine ek olarak ayak ortası osteotomisi (küboid ve kuneiform) ve 1. tarsometatarsal ekleme artrodez ameliyatları gerekebilir. Üçlü artrodez ise son tercih olarak düşünülmelidir. Tedavi sonrası deformite tekrarlaması veya aşırı düzeltme görülebilir.

\section{Planovalgus Ayak}

Planovalgus ayak etiyolojisi çok etkenlidir. Anormal kas kuvveti, basma sırasında aşırı yüklenmeler, kemik dizilim bozukluğu, ligamentöz yetersizlik ve genetik eğilim etiyolojide yer almaktadır. Ambulasyonu olmayan kuadriplejik çocuklarda yapılan EMG çalışmalarında peroneal kaslarda hiperaktivite gözlense de, mobilize çocuklarda peroneal hiperaktivite gözlenmez. Yürüme veya ayakta durma sırasında alt ekstremiteye binen yüklerin çoğunu, diz veya ayak bileği yerine, subtalar eklem abzorbe eder. Ayrıca, gastroknemius ve soleusdaki kontraktür de subtalar eklemin çökmesine zemin hazırlar. Çocuklarda büyük oranda kıkırdak yapıda olan tarsal kemikler de anormal yüklenmeler sonucu deforme olur.

Subtalar eklemin anatomik yapısı iyi incelenmiştir. Temel olarak asetabulum pedis kavramı üzerine yoğunlaşıımıştır. Bu kavram, talus başının, navikula ve kalkaneustan oluşan yuva içindeki hareketini tarif etmektedir. Bu sayede, ön ayak oldukça rahat hareket imkanı bulur. Ancak her plandaki hareketi posterior subtalar faset eklemi kısıtlar. Planovalgus deformitesinde, ayak önü talusa göre dış rotasyon, valgus ve dorsifleksiyona gider. Bu sayede, talus başının anterior ve inferior örtünmesi azalır. Subtalar eklemin posterior fasetinde de posteriora subluksasyon görülür, bu da dış rotasyon ve dorsifleksiyonu arttırır. Bazı planovalgus ayaklarda valgus ön plandayken, bazılarında dış rotasyon ve dorsifleksiyon daha belirgindir. Ayağın normal anatomisi bozulmaya başladıkça, üzerine binen yüklenmeler deformitenin artmasına neden olur. Deformite ilerledikçe kalkaneus talusa göre dorsifleksiyona, talus ve kalkaneus da tibiaya göre ekin pozisyonuna gelir. Bu patolojinin gelişimine gastroknemius konraktürünün etkisi tam gösterilememiştir. Ekinovarus deformitesine göre kontraktürün daha az olduğu düşünülmektedir. Eğer gastrosoleus kontrakte değil, ancak çok zayıfsa, tibialis anterioru antagonize etmek için parmak fleksörleri daha fazla çalışır ve kavovalgus deformitesinin gelişmesine neden olur.

Asetabulum pedis, deformite ilerledikçe disloke olur, kalkaneus dorsifleksiyonu artar ve sinus tarsi tamamen oblitere olur. Ayak bileğinin lateraline binen yüklerin artması sonucu, büyüme plağının lateralinde büyüme yavaşlar ve ayak bileği valgusu gelişir. Zamanla ayak arkası bu şekilde stabil hale gelir. Yük aktarımı tamamen ayak ortası üzerinden yapılır. Ayak mediyalinde navikula ve kuneiform üzerinden yük aktarımı olur. Tibiada dış rotasyonun da gelişmesi ile tersiyer deformiteler ortaya çıkar.

Planovalgus ayakta tedavi planlaması yapılırken en büyük eksiklik, literatürde bu ayakların doğal seyri ile ilgili kapsamlı çalışmaların olmamasıdır. Ayrıca, cerrahi tedavilerin de karşılaştırmalı sonuçları bulunmamaktadır. Cerrahi tedavi deformitenin derecesine ve çocuğun fonksiyonel kapasitesine göre deformitenin engellenmesi, rekonstrüksiyon ve kurtarıcı girişimler şeklinde yapılmaktadır.

Erken yaşlarda planovalgus deformitesinin engellenmesi için peroneal uzatma öneren yazılar vardır. Ancak bu, doğal seyriyle ilgili çalışmalar yetersiz olduğu için, rutin kullanıma girmeyen bir metoddur. Bu nedenle, ortez kullanımını erken dönemde engelleme amacıyla tavsiye edilmektedir.

Ortez kullanımı ile kontrol edilemeyen ve bası yaraları ve ağıı gelişen durumlarda cerrahi tedavi gerekir. Beş yaşından önce deformite düzeltme, nadir durumlar haricinde tavsiye edilmez. Deformite gelişimi yavaş olduğu için, beş yaş altında deformite tam değerlendirilemeyebilir. Beş-yedi yaş arasında rekonstrüksiyon ideal gibi düşünülmelidir.

Lateral kolon uzatma, asetabulum pedise giren intra-artiküler bir cerrahidir. Anterior ve orta fasetler arasına lateralden kalkaneusa osteotomi yapılır ve osteotomi bölgesi distrakte edilerek, araya kemik grefti veya implant yerleştirilir. Bu şekilde ayak önü iç rotasyon ve supinasyona getirilerek talus başının mediyalden örtünmesi arttırılmış; aynı zamanda, kalkaneusun dorsifleksiyona gelerek sinus tarsiyi bloke etmesi engellenmiş olur. Subtalar eklem hareketleri korunur. Erken dönem deformitelerin düzeltilmesinde ideal bir metoddur. Destekli mobilize hastalarda, mobilize olmayan hastalara göre daha çok tercih edilir. Motor kontrolü iyi olmayan, ancak ev içi mobilize hastalar$\mathrm{da}$ ise subtalar artrodez tercih edilir. Bu, kalıcı düzeltme sağlarken, subtalar eklem hareketini ortadan kaldırır. Daha ileri deformitelerde, kalkaneoküboid eklem subluksasyonunun da olduğu olgularda, kalkaneoküboid eklem eksize edilerek o bölgeden lateral kolon uzatma yapılabilir. Subtalar eklem artrodezi yapılırken, anatomik eklem redüksiyonu sağlanmaIı, ön-arka planda talus ile kalkaneus arasındaki açı $20-30^{\circ}$ arasına getirilmelidir. Tibial torsiyon ve ayak bileği valgusu mevcutsa, osteotomi ve hemiepifizyodez ile düzeltilmelidir. İleri valgus deformitelerinde ise 
kurtarıcı girişim olarak üçlü artrodez yapılabilir. Bu, ayrıntılı planlama gerektiren bir girişimdir ve eklemlerin rijid tespiti gerekir.

\section{Ayak Ortası ve Ayak Önü Girişimleri}

Hemen hemen tüm planovalgus ayaklarda ayak önü supinasyonu mevcuttur ve ayak arkası deformitesi düzeltildikten sonra daha belirgin hale gelir. Supinasyon, tibialis anteriorun çekmesine karşılık peroneus longusun yetersiz kalmasına bağlıdır. Küçük çocuklarda ayak arkası deformitesinin düzeltilmesi ile supinasyonda düzelme sağlanır. Ancak, ileri deformitelerde navikülokuneiform eklemde sabit supinasyon görüldüğü için cerrahi düzeltme gerekir. Navikülokuneiform eklemin plantar yüzüne, açık kama osteotomisi ile beraber tibialis anteriorun lateral kuneiforma transferi, uygun bir cerrahi tercih olabilir. İleri deformitelerde navikülokuneiform eklemden açık kama osteotomisi yeterli olmaz, talonaviküler eklemden düzeltme de gerekebilir. Bu durumda, tespit için mediyalden plaklama uygun olacaktır.

\section{SONUÇ}

Serebral palsi hastalarında, kas dengesinin, kontrolünün ve tonunun bozulması nedeniyle, ayak deformiteleri sık görülür. En sık görülen segmental dizilim bozuklukları, ekinus, planovalgus ve ekinovarustur. Hafif esnek deformiteler için; ortezleme, germe egzersizleri ve tonus azaltıcı medikal işlemler yararlı olabilir. Ayak deformitelerinin doğal seyri önceden kestirilemez, ancak zaman içinde deformitenin ilerlemesi ve sertleşmesi beklenir. Böyle durumlarda cerrahi işlemler gerekir. Yumuşak doku operasyonları, osteotomi, artrodez veya bunların kombinasyonları uygulanabilir. Tedavi planlanırken, deformitenin ciddiyetine ek olarak, hastanın yaşı ve fonksiyonel kapasitesi de değerlendirilmelidir.

\section{KAYNAKLAR}

1. O'Connell PA, D'Souza L, Dudeney S, Stephens M. Foot deformities in children with cerebral palsy. J Pediatr Orthop 1998;18(6):743-7. Crossref

2. Pin $T$, Dyke $P, C$ han $M$. The effectiveness of passive stretching in children with cerebral palsy. Dev Med Child Neurol 2007; 48(10):855-62. Crossref

3. Williams SA, Elliott C, Valentine J, Gubbay A, Shipman $\mathrm{P}$, Reid $\mathrm{S}$. Combining strength training and botulinum neurotoxin intervention in children with cerebral palsy: the impact on muscle morphology and strength. Disabil Rehabil 2013;35(7):596-605. Crossref
4. Gormley ME Jr, Krach LE, Piccini L. Spasticity management in the child with spastic quadriplegia. Eur J Neurol 2001;8 Suppl 5:127-35. Crossref

5. Sung KH, Chung CY, Lee KM, Akhmedov B, Lee SY, Choi IH, Cho TJ, Yoo WJ, Park MS. Long term outcome of single event multilevel surgery in spastic diplegia with flexed knee gait. Gait Posture 2013;37(4):536-41. Crossref

6. Thomason P, Selber P, Graham HK. Single Event Multilevel Surgery in children with bilateral spastic cerebral palsy: a 5 year prospective cohort study. Gait Posture 2013;37(1):23-8. Crossref

7. Houx L, Lempereur M, Rémy-Néris O, Brochard S. Threshold of equinus which alters biomechanical gait parameters in children. Gait Posture 2013;38(4):582-9. Crossref

8. Lee SJ, Sung IY, Jang DH, Yi JH, Lee JH, Ryu JS. The effect and complication of botulinum toxin type a injection with serial casting for the treatment of spastic equinus foot. Ann Rehabil Med 2011;35(3):344-53. Crossref

9. Park ES, Rha DW, Yoo JK, Kim SM, Chang WH, Song SH. Short-term effects of combined serial casting and botulinum toxin injection for spastic equinus in ambulatory children with cerebral palsy. Yonsei Med J 2010;51(4):579-84. Crossref

10. Bennet GC, Rang M, Jones D. Varus and valgus deformities of the foot in cerebral palsy. Dev Med Child Neurol 1982;24(5):499-503. Crossref

11. Sees JP, Miller F. Overview of foot deformity management in children with cerebral palsy. J Child Orthop 2013;7(5):373-7. Crossref

12. Evans D. Calcaneo-valgus deformity. J Bone Joint Surg $\mathrm{Br}$ 1975;57-B(3):270-8. Crossref

13. Ettl V, Wollmerstedt N, Kirschner S, Morrison R, Pasold E, Raab P. Calcaneal lengthening for planovalgus deformity in children with cerebral palsy. Foot Ankle Int 2009;30(5):398404. Crossref

14. Kadhim M, Holmes L Jr, Church C, Henley J, Miller F. Pes planovalgus deformity surgical correction in ambulatory children with cerebral palsy. J Child Orthop 2012;6(3):21727. Crossref

15. Huang CN, Wu KW, Huang SC, Kuo KN, Wang TM. Medial column stabilization improves the early result of calcaneal lengthening in children with cerebral palsy. J Pediatr Orthop B 2013;22(3):233-9. Crossref

16. Senaran H, Yilmaz G, Nagai MK, Thacker M, Dabney KW, Miller F. Subtalar fusion in cerebral palsy patients: results of a new technique using corticocancellous allograft. J Pediatr Orthop 2011;31(2):205-10. Crossref

17. Rathjen KE, Mubarak SJ. Calcaneal-cuboid-cuneiform osteotomy for the correction of valgus foot deformities in children. J Pediatr Orthop 1998;18(6):775-82. Crossref

18. Tenuta J, Shelton YA, Miller F. Long-term follow-up of triple arthrodesis in patients with cerebral palsy. J Pediatr Orthop 1993;13(6):713-6. Crossref

19. Michlitsch MG, Rethlefsen SA, Kay RM. The contributions of anterior and posterior tibialis dysfunction to varus foot deformity in patients with cerebral palsy. J Bone Joint Surg Am 2006;88(8):1764-8. Crossref

20. Scott AC, Scarborough N. The use of dynamic EMG in predicting the outcome of split posterior tibial tendon transfers in spastic hemiplegia. J Pediatr Orthop 2006;26(6):777-80. Crossref 